\title{
ANÁLISE COMPARATIVA DA GESTÃO AMBIENTAL NA CERTIFICAÇÃO FAIR TRADE: PRINCIPAIS DIFERENÇAS ENTRE NORMAS PÚBLICAS E PRIVADAS.
}

\author{
Gabriela Pinheiro ${ }^{1}$
}

Douglas Ken Nagai ${ }^{2}$

\section{RESUMO}

Para acessar oportunidades de mercado diferenciadas, os produtores de café têm buscado mecanismos de certificação visando melhorar seus meios de comercialização e produção. Nesse contexto, as normas públicas nacionais trazem requisitos mínimos a serem cumpridas para a exploração adequada do setor. Já as normas privadas possuem exigência mais elevada, porém permitem 0 acesso a ganhos diferenciados. Neste sentido, o presente artigo tem o objetivo de descrever as principais diferenças entre as normas públicas e as normas estabelecidas pela certificação Fairtrade Internacional para café, no que tange a gestão ambiental. Visase analisar qual a distância entre elas e se há similaridade em alguns pontos, bem como verificar se as normas públicas dão respaldo para certificação Fairtrade.

PALAVRAS-CHAVE: Certificação. Normas Públicas. Gestão Ambiental.

\footnotetext{
${ }^{1}$ Mestranda em Agronegócio e Desenvolvimento, Universidade Estadual Paulista - UNESP, Campus de Tupã. E-mail. gabipinheiro_adv@hotmail.com

${ }^{2}$ Mestrando em Agronegócio e Desenvolvimento, Universidade Estadual Paulista - UNESP, Campus de Tupã. E-mail. nagaikd@gmail.com
} 


\title{
COMPARATIVE ANALYSIS OF ENVIRONMENTAL MANAGEMENT AT FAIRTRADE CERTIFICATION: MAIN DIFFERENCES BETWEEN PUBLIC AND PRIVATE STANDARDS
}

\begin{abstract}
To access opportunities for differentiated markets, coffee farmers have sought certification mechanisms to improve their means of production and marketing. In this context, national public standards bring minimum requirements to be met for proper operation of the sector. Private standards usually have higher requirements, but allow access to differentiated gains. In this sense, the present article aims to describe the main differences between public norms and the standards established by the International Fairtrade certification for coffee, as it pertains to environmental management. The overall objective is to verify that the distance between them and if there is similarity in some points and check if the rules give public backing for Fairtrade certification.
\end{abstract}

KEY-WORDS: Certification. Public Standards. Environmental Management.

\section{ANÁLISIS COMPARATIVO DE GESTIÓN AMBIENTAL EN LA CERTIFICACIÓN FAIRTRADE: PRINCIPALES DIFERENCIAS ENTRE NORMAS PÚBLICAS Y PRIVADAS}

\begin{abstract}
RESUMEN
Para oportunidades de acceso para el mercado diferenciado, los productores de café han buscado mecanismos de certificación para mejorar sus medios de producción y comercialización. En este contexto, las normas públicas nacionales traer requisitos mínimos que deben cumplir para un correcto funcionamiento del sector. Las normas privadas son ya más alta exigencia, pero permiten el acceso a las ganancias diferenciadas. En este sentido, el presente artículo tiene como objetivo describir las principales diferencias entre las normas públicas y las normas establecidas por la certificación internacional de Comercio Justo para el café, en lo que respecta a la gestión ambiental. Que pretende analizar la distancia entre ellos y si hay similitud en algunos puntos y comprobar si las reglas le dan el respaldo público para la certificación Fairtrade.
\end{abstract}

PALABRAS-CLAVE: Certificación. Normas públicas. Gestión Ambiental 
Volume 10, Número 5, 2014

Direito Ambiental, Políticas Públicas e Sociedade

\section{INTRODUÇÃO}

Padrões públicos e privados para a segurança e qualidade dos alimentar são de suma importância para gerenciar o mercado de alimentos. Entende-se que as normas públicas são consideradas como uma resposta às falhas de mercado e abrangem uma avaliação obrigatória de riscos. No que tange a criação de normas privadas, elas vêm se tornando uma característica marcante no mercado internacional alimentar e, na maioria das vezes, apresentam padrões de exigibilidade mais elevados que os padrões públicos (HOBBS, 2010).

Segundo Maertens e Swinnen (2008) diversos fatores têm cooperado para o aumento acentuado de normas alimentares nos últimos anos, dentre elas tem-se o crescimento da renda dos consumidores, aumentando a demanda pela qualidade e segurança do produto e; mudança de hábitos alimentares e consciência sobre os problemas e danos à saúde.

Um dos fatores mais importantes da regulamentação estatal são os regulamentos fitossanitários, que visam garantir a qualidade dos produtos agrícolas produzidos e consumidos no país, bem como servem de barreiras para impedir a importação de determinados insumos (BONONI, 2005).

No entendimento de Hobbs (2010) as normas públicas reguladoras do setor agroalimentar podem ser consideradas como uma resposta a uma falha de mercado, pois são frequentemente implementadas na presença de externalidades negativas, para garantir o fornecimento de bens públicos ou para mitigar a assimetria de informações.

É neste contexto que surgem as barreiras não tarifárias do comércio internacional alimentício tendo em vista que há uma grande divergência entre as normas públicas de um país para outro. Tais diferenças existem porque as normas dependem de aspectos internos de cada Estado-Nação, gerando barreiras no âmbito da exportação e importação de produtos, pois, nem sempre as normas públicas, de caráter obrigatório, se coadunam entre si. 
Volume 10, Número 5, 2014

Direito Ambiental, Políticas Públicas e Sociedade

As barreiras não tarifárias podem ser reguladas a nível global pela Organização Mundial do Comércio (OMC), através do Acordo sobre Aplicação de Medidas Sanitárias e Fitossanitárias (Acordo SFS), sendo decorrentes de tratados multilaterais ou bilaterais ou, podem ser reguladas nacionalmente. Barreiras não tarifárias podem ser barreiras quantitativas, sanitárias, fitossanitárias, cambiais, ambientais, de licenciamento de importação, entre outras (NETO, 2005).

Assim, este trabalho tem como objetivo analisar qual a distância entre elas e se há similaridade em alguns pontos, bem como verificar se as normas públicas dão respaldo para certificação Fairtrade.

\subsection{Certificação Fairtrade}

As certificações privadas como a Fairtrade surgem como uma forma de sinalizar ao mercado mecanismos de governança de natureza privada. Em geral esses mecanismos mostram ao mercado características não previstas no ambiente regulatório na governança pública. (HATANAKA, BAIN, BUSCH, 2005).

Os custos para certificação podem ser expressivos, principalmente ao nos atermos a pequenos e médios produtores rurais, no entanto, as vantagens decorrentes da certificação são perceptíveis. Além de garantir a informação ao consumidor sobre o produto adquirido, trazendo segurança em relação à qualidade, os produtores detentores de produtos certificados possuem maior espaço no mercado internacional (NUNES ET AL, 2013).

A função das certificações pode ser definida por meio de várias óticas. Dorr e Grote (2009), afirmam que a certificação serve como forma de comunicação ao longo de uma cadeia produtiva, pois demonstra a um potencial comprador que o fornecedor cumpriu com determinadas normas. Para Lourenzani, Lourenzani e Pigatto (2011), as certificações têm aspectos estratégicos que fornecem melhorias ambientais para os produtores rurais. Cunha, Saes e Mainville (2013), analisaram que as certificações também servem como um redutor de custos de transação uma vez que promovem 
Volume 10, Número 5, 2014

Direito Ambiental, Políticas Públicas e Sociedade

redução de assimetrias informacionais, para consumidores e fornecedores no setor agropecuário.

Kilian et al.(2006) afirmam que as certificações sustentáveis como a Fairtrade, aumentam os desafios gerenciais para se obter maior renda e benefícios. Os autores afirmam que esse aumento do desafio leva os produtores rurais a elevarem seus níveis de gestão e criar planejamentos a longo prazo.

Segundo a Fairtrade International (2014), a certificação Fairtrade é a garantia de uma abordagem alternativa de comércio baseada na parceria entre produtores e consumidores, que se propõe a melhorar as formas de negociação e troca para garantir o futuro dos membros envolvidos na atividade.

A certificação Fairtrade possui como desafio conciliar abordagens de mercado e crescimento econômico com formas de criação de valor social e desenvolvimento dos agentes envolvidos, colaborando inclusive na formulação de políticas de desenvolvimento (REYNOLDS, MURRAY e TAYLOR, 2004). Observa-se assim, uma preocupação quanto à sustentabilidade dos negócios, que vai além de uma abordagem voltada meramente para resultados econômicos.

Neste sentido, a certificação Fairtrade apresenta alguns requisitos de adequação para pequenos produtores, no que tange ao preço dos produtos e à produtividade. Por sua vez, o ordenamento jurídico nacional em vigor dispõe, através de diversos tipos de normativas, os requisitos técnicos para a produção de café.

\section{DESENVOLVIMENTO}

Para a realização desta pesquisa e cumprimento do objetivo proposto, foi feita uma análise comparativa entre as normas Fairtrade e norma pública, com caráter qualitativo que, conforme Dalfovo, Lana e Silveira (2008) definem como ideal para situações em que os números não servem como indicadores das informações coletadas, mas sim, palavras e interpretações por meio da relação com a teoria levantada

Quanto aos objetivos pode ser classificada como exploratória e quanto aos procedimentos, esta pesquisa é predominantemente documental. A pesquisa 
documental, segundo Sá-Silva, Almeida e Guindani (2009), é capaz de gerar novos conhecimentos por meio da investigação de documentos escritos e interpretações entre os registros. Os documentos referentes às normas do Fairtrade foram levantados junto ao site institucional da Fairtrade International, sendo consideradas para este trabalho as versões mais atualizadas das normas gerais para pequenos produtores, denominadas "Standards for Small Producers Organisations" (2011). Normas específicas para os produtores e organizações Fairtrade envolvidos na atividade cafeeira também foram levantadas e comparadas junto ao ordenamento jurídico brasileiro, no que tange às normas públicas referentes à produção de café.

Após a coleta de dados, foi elaborada uma planilha com agrupamentos para mensurar os principais assuntos correlatos e divergentes entre norma privada e norma pública. Para este trabalho, todas as normativas foram consideradas com igual relevância, sem ponderar dificuldades de obtenção.

Os agrupamentos definidos pelos autores foram: formas de descrição e riscos de produção, manejo de pragas, manuseio de fertilizantes e; uso de Organismos Geneticamente modificados - OGMs. Estes agrupamentos foram baseados na certificação Fairtrade, uma vez que o Estado possui maior número de regras e normas para se gerar o desenvolvimento em um território.

A tabela abaixo demonstra os níveis de semelhanças entre as normas:

Tabela 1: Parâmetros de análise das semelhanças

\begin{tabular}{|c|c|c|c|}
\hline $\begin{array}{c}\text { Categorias } \\
\text { analisadas }\end{array}$ & Semelhança & $\begin{array}{c}\text { Relativa } \\
\text { semelhança }\end{array}$ & $\begin{array}{c}\text { Nenhuma } \\
\text { semelhança }\end{array}$ \\
\hline $\begin{array}{c}\text { Informações sobre a } \\
\text { produção }\end{array}$ & & $\mathrm{X}$ & \\
\hline $\begin{array}{c}\text { Riscos e } \\
\text { monitoramento da } \\
\text { atividade }\end{array}$ & & $\mathrm{X}$ & \\
\hline Manejo de pragas & $\mathrm{X}$ & $\mathrm{X}$ & \\
\hline $\begin{array}{c}\text { Manuseio de } \\
\text { fertilizantes }\end{array}$ & & & $\mathrm{X}$ \\
\hline Uso de transgênicos & & & \\
\hline
\end{tabular}

Fonte: Elaborado pelos autores (2014) 
Volume 10, Número 5, 2014

Direito Ambiental, Políticas Públicas e Sociedade

Informações da Produção: No que tange a comparação das formas de informação da produção, as normas mostraram-se relativamente semelhantes. Em relação às informações sobre os produtos repassados aos colaboradores, a norma Fairtrade exige que seus membros produtores tenham conhecimento das exigências ambientais e trabalhistas envolvidas na produção de café, bem como de gestão, e não apenas aspectos operacionais. A norma pública equivalente analisada (IN no 49/2013 - MAPA - Normas técnicas para produção integrada de café) prevê que os funcionários devem estar cientes sobre suas funções e responsabilidades na propriedade, mantendo um documento comprobatório com anuência dos mesmos, bem como manter responsáveis técnicos capacitados acerca da produção.

É possível perceber neste caso que a norma Fairtrade exige maior conhecimento por parte dos envolvidos na produção e especifica as questões ambientais e trabalhistas. A norma pública neste caso, não especifica quais são as funções e responsabilidades de fato, induzindo a interpretação de que estas são exclusivamente aspectos operacionais.

Riscos e monitoramento da atividade: Outra comparação feita foi quanto aos riscos e monitoramento de não cumprimento da norma. A norma Fairtrade neste caso exige que seja feito um planejamento com as possibilidades de não cumprimento das normas, com uma periodicidade de três anos. É perceptível que a Fartrade possui norminativas de caráter preventivo, no que tange ao seu autocumprimento. A norma pública nesse caso não prevê este planejamento. Nesta análise é possível perceber que o Estado considera que a lei seja assegurada independente da situação, com caráter mandatório.

Manejo de pragas: A análise dos dados, no que tange ao manejo de pragas e manuseio de fertilizantes, mostrou que existe semelhança com o sistema de adequação nacional regido pelas normas públicas. A norma Fairtrade nesse caso estipula a necessidade do Manejo adequado de pesticidas, agrotóxicos e demais produtos químicos; Implementação de medidas de segurança - EPIs e o armazenamento de produtos químicos adequado, de forma a minimizar riscos. Já a disposição pública referente ao uso de agrotóxicos está expressa na Lei Federal no 7.802/89. Referida lei dispõe que a utilização de agrotóxicos apenas poderá ocorrer 
Volume 10, Número 5, 2014

Direito Ambiental, Políticas Públicas e Sociedade

em consonância com as diretrizes e exigências dos órgãos federais, buscando minimizar os riscos por ele causados. Quanto ao uso dos equipamentos de segurança, expresso pelo Decreto Lei 5.452/43, especifica que a utilização obrigatória de equipamento de proteção individual - EPIs, os quais devem, obrigatoriamente, ser fornecidos pelo empregador.

Manuseio de fertilizantes: No que tange ao manuseio de fertilizantes, foi encontrada relativa semelhança. A norma Fairtrade estipula que o treinamento para os membros da organização sobre o uso adequado de fertilizantes deve ser fornecido. A norma pública relativamente semelhante, neste caso é o Decreto № 4.954/04. Respectivo decreto dispõe sobre a produção e comercialização dos fertilizantes, dando diretrizes para o uso adequado do mesmo.

É possível perceber que nesse caso a norm pública as especifica as diretrizes do uso de fertilizantes atrelado a instruções no produto. No caso da norma Fairtrade, faz-se necessária a capacitação dos produtores que irão utilizá-las.

Organismos Geneticamente modificados - No caso do uso dos OGMs há uma divergência em relação aos Organismos Geneticamente Modificados - OGM. A Fairtrade internacional veda sua utilização e não permite o plantio paralelo a produções não modificadas. referentes as normas públicas, apesar de haver um forte controle legal sobre o uso de OGMs, conforme expresso na Lei oㅜ 11.105/05, que estabelece normas de segurança e mecanismos de fiscalização sobre a construção, o cultivo, a produção, a manipulação, o transporte, a transferência, a importação, a exportação, o armazenamento, a pesquisa, a comercialização, o consumo, a liberação no meio ambiente e o descarte de organismos, é permitido o uso.

\section{CONCLUSÃO}

Ante a estas considerações, podemos concluir que os requisitos do Fairtrade internacional pouco se assemelham com as normas públicas nacionais voltadas para o setor cafeeiro. Em alguns pontos, podemos perceber que as exigências do Fairtrade são maiores que as mínimas estipuladas pelas normas públicas, como uso no caso do uso de transgênicos e manuseio de fertilizantes. A norma Fairtrade veda 
completamente o uso de transgênicos, impossibilitando os produtores a se apropriarem dos benefícios de produtividade e resistência climática fornecidos por essa variedade.

Uma grande dificuldade percebida é que o ordenamento jurídico nacional se utiliza de diversas espécies normativas para tratar do mesmo setor, ou seja, são inúmeras leis, resoluções, decretos, instruções normativas, todas tratando sobre o setor agroindustrial e outras especificamente tratando sobre o café. É perceptível que o pequeno produtor possui dificuldades em cumprir todos os ditames legais pela dificuldade de se adequar e de encontrar todas as normativas pertinentes ao setor que atua. Neste trabalho foram trabalhados alguns aspectos ligados à gestão ambiental e ao tipo de produção. Fora constatado que existe certa distância entre as normas públicas e a certificação Fairtrade. No caso de aspectos ligados a produção e especificação de insumos existem semelhanças entre as normas, como visto no caso do Manejo das pragas. Entretanto as diferenças aparecem quando elementos ligados a gestão das propriedades e colaboradores envolvidos na atividade. Outra grande diferença está no posicionamento que as normas têm em relação ao uso de OGMs.

\section{REFERÊNCIAS}

BONONI, Alexandre Bottino; NETO, Orlando Celso da Silva et.al; SANTOS, Márcia Walquíria Batista dos; QUEIROZ, João Eduardo Lopes (coordenadores). DIREITO DO AGRONEGÓCIO. Belo Horizonte: Editora Fórum, 2005.

BRASIL. Decreto no 4.954, de 14 de janeiro de 2004. Aprova o Regulamento da Lei no 6.894, de 16 de dezembro de 1980, que dispõe sobre a inspeção e fiscalização da produção e do comércio de fertilizantes, corretivos, inoculantes ou biofertilizantes destinados à agricultura, e dá outras providências. Disponível em http://www.planalto.gov.br/ccivil_03/_ato2004-

2006/2004/decreto/d4954.htm. Acesso em 20/07/2014.

Decreto-Lei ํㅜ 5.452, de 1ำ de maio de 1943. Consolidação das Leis Trabalhistas. Vade Mecum Saraiva. 15a Edição. Ed. Saraiva, 2013.

. Lei no 7.802 , de 11 de julho de 1989. Dispõe sobre a pesquisa, a experimentação, a produção, a embalagem e rotulagem, o transporte, o armazenamento, a comercialização, a propaganda comercial, a utilização, a importação, a exportação, o destino final dos resíduos e embalagens, o registro, a classificação, o controle, a inspeção e a fiscalização de agrotóxicos, seus componentes e afins, e dá outras providências. Disponível em http://www.planalto.gov.br/ccivil_03/leis//7802.htm. Acesso em 20/07/2014. 
convencionais e orgânicos no Brasil e nos Estados Unidos: a influência do custo de transação e de mensuração. São Paulo: Revista de Administração. v. 48, 2013, p. 341-358.

DALFOVO, M. S.; LANA, R. A.; SILVEIRA, A. Métodos quantitativos e qualitativos: um resgate teórico. Revista Interdisciplinar Científica Aplicada, Blumenau: v.2, n.4, p.01-13, 2008.

DORR, Andrea Cristina; GROTE, Ulrike. The Role of Certification in the Brazilian Fruit Sector. Rio de Janeiro: Revista de Economia Contemporânea. Volume 13, 2009, p. 539-571.

FAIRTRADE INTERNATIONAL. What is Fairtrade. Disponível em:< http://www.fairtrade.net/what-isfairtrade.html>. Acesso em: 20 set. 2014.

. Fairtrade Standard for Small Producer Organizations. 2011-2016. Disponível em <http://www.fairtrade.net/small-producer-standards.html>. Acesso em 20/07/2014.

. Critério do Comércio Justo para café de organizações de Pequenos Produtores. 20112013. Disponível em http://www.fairtrade.net/small-producer-standards.html. Acesso em 20/07/2014. HATANAKA, M.; BAIN, C.; BUSCH, L. Third-party certification in the global agrifood system. Food Policy, 3 ed, n. 30, p. 354-369, 2005.

HOBBS, Jill E. Public and Private Standards for Food Safety and Quality: International Trade Implications. Canadá: The Estey Center Journal of International Law and Trade Policy. Volume 11, 2010, p. 136-152.

KILIAN, B.; JONES, C.; PRATT, L.; VILLALOBOS, A. Is sustainable agriculture a viable strategy to improve farm income in Central America? A case study on coffee. Journal of Business Research. v. 53, p. 322-330, 2006.

LOURENZANI, Ana Elisa Bressan Smith; LOURENZANI, Wagner Luiz; PIGATTO, Gessuir. Certificação para a fruticultura como estratégia de acesso a mercados. Agronegócio: panorama, perspectivas e influência do mercado de alimentos certificados. Curitiba: Editora Appris, 2011, 1르 Ed.

MAERTENS, M.; SWINNEN, J. F. M. Standards as barriers and catalysts for trade, growth and poverty reduction. Journal of International Agricultural Trade and Development. V. 4, Issue 1, p. 47-61, 2008.

NUNES, R.; SILVA, V. L dos. S.; SAES, M. S. M.; SOUSA, R. N. R. L de.; SOUZA, R de. C. Incentives to differentiation strategies for Brazilian coffee producers. Revista de Economia e Administração, v. 12, n. 2, p. 165-179, 2013.

RAYNOLDS, L. T; MURRAY, D; TAYLOR, P. L. Fair Trade Cofee: Building producer capacity via global networks. Journal of International Development. V. 16. 2004. P. $1109-1121$.

SÁ-SILVA, J. R; ALMEIDA, C. D; GUINDANI, J.F. Pesquisa documental: pistas teóricas e metodológicas. Revista Brasileira de História \& Ciências Sociais. Ano I, número I, julho 2009. 